\title{
POTENSI DAN MODEL PENGEMBANGAN SPESIES TUMBUHAN DI HUTAN LINDUNG SARAMBU' ALLA KABUPATEN LUWU UTARA
}

\author{
(Potential And Plant Species Development Model In Sarambu Alla Protected Forests, North \\ Luwu District)
}

\author{
Hadijah Azis Karim ${ }^{1)}$, Afandi Ahmad ${ }^{2)}$ \\ ${ }^{1,2)}$ Dosen Fakultas Kehutanan, Universitas Andi Djemma Palopo \\ e-mail: hadijahaziskarim@gmail.com
}

\begin{abstract}
Sarambu Alla Protection Forest is a state forest area located in Sabbang District, North Luwu Regency. In order to support the objectives and functions of the area as mentioned above, various basic information is needed related to the potential contained in the forest. One of the most important information is information about the potential and diversity of plant species. This research will be very useful for efforts to manage and develop Biodiversity and Ecosystem Services in order to preserve the diversity of local, endemic and rare plant plasmanutfah resources, especially those originating from the North Luwu region or endemic to Sulawesi Island in general, as well as the potential development of natural tourist attraction objects contained in it for the use of natural tourism or ecotourism. This activity carried out through plant species exploration will be carried out purposively using a single plot system measuring 20 $m \times 20 \mathrm{~m}$. Based on the results of analysis of vegetation in the Sarambu Alla Protected Forest Area, there were 64 species found in 25 observation plots. There are 32 species with tree habitus that have potential as commercial wood, home building materials, and fruit can be consumed as well as medicinal plants. These species can be used as development models, both planted on community-owned land, green open spaces and on land or forest areas that have been damaged or disturbed.
\end{abstract}

Keyword: Biodiversity, Plant identification, Sarambu Alla' Protection Forest, Species improvement

\begin{abstract}
Abstrak
Hutan Lindung Sarambu Alla merupakan kawasan hutan negara yang terletak di Kecamatan Sabbang Kabupaten Luwu Utara. Dalam rangka mendukung tujuan dan fungsi kawasan sebagaimana tersebut di atas, maka dibutuhkan berbagai informasi dasar terkait dengan potensi yang terkandung di kawasan tersebut. Salah satu informasi yang terpenting adalah informasi mengenai potensi dan keanekaragaman spesies tumbuhan. Penelitian ini akan sangat berguna bagi upaya pengelolaan dan pengembangan Keanakeragaman Hayati dan Ekosistem dalam rangka melestarikan keanekaragaman sumberdaya plasmanutfah tumbuhan lokal, endemik, dan langka khususnya yang berasal dari wilayah Luwu Utara atau endemik Pulau Sulawesi secara umum, serta pengembangan potensi obyek daya tarik wisata alam yang terkandung di dalamnya untuk pemanfaatan wisata alam atau ekowisata. Kegiatan ini diselenggarakan melalui explorasi spesies tumbuhan akan dilakukan secara purpossive dengan menggunakan sistem plot tunggal berukuran $20 \mathrm{~m}$ x $20 \mathrm{~m}$. Berdasarkan hasil analisis vegetasi di Kawasan Hutan Lindung Sarambu Alla menunjukkan bahwa terdapat 64 spesies yang ditemukan pada 25 plot
\end{abstract}


pengamatan. Terdapat 32 spesies dengan habitus pohon memiliki potensi sebagai kayu komersial, bahan bangunan rumah, dan buahnya dapat dikonsumsi serta tumbuhan obat. Spesies tersebut bisa dijadikan model pengembangan baik ditanam pada lahan milik masyarakat, ruang terbuka hijau dan pada lahan atau kawasan hutan yang telah rusak atau terganggu.

Kata kunci: Hutan Lindung Sarambu' Alla, Identifikasi Tumbuhan, Keanekaragaman Jenis, Pengembangan Spesies

\section{PENDAHULUAN}

Keanekaragaman hayati merupakan kelimpahan berbagai spesies sumberdaya alam hayati (tumbuhan dan hewan) yang terdapat di muka bumi. Salah satu unsur dari keanekeragaman hayati adalah keanekeragaman spesies, yakni karakteristik tingkatan dalam komunitas berdasarkan organisasi biologisnya, yang dapat digunakan untuk menyatakan struktur komunitasnya. Keanekaragaman spesies adalah sebagai gabungan antar jumlah spesies dan jumlah individu masing-masing spesies dalam komunitas. Bahkan secara kuantitatif keanekaragaman spesies didefinisikan sebagai jumlah spesies yang ditemukan pada komunitas, sedangkan ukurannya disebut kekayaan spesies (Indriyanto 2006; Sofiah 2007).

Pulau Sulawesi terkenal dengan keanekaragaman hayatinya yang sangat unik di antara pulau lainnya di Indonesia. Keunikan keanekaragaman hayati di pulau Sulawesi terkait dengan sejarah biogoegrafi pulau tersebut yang terbentuk dari perpaduan antara dua pulau yang terjadi melalui pergerakan dua lempeng utama bumi yaitu lempeng Laurasia dan Gondwana dan berlokasi di antara dua benua, yaitu Asia dan Australia (Whitten et al. 1999). Keanekaragaman tumbuhan dan satwa di pulau Sulawesi merupakan perpaduan antara keanekaragaman hayati dari kedua benua tersebut. Letak wilayah dan sejarah biogegrafinya yang sangat unik dan kompleks mengakibatkan ekosistem yang ada di Pulau
Sulawesi saat ini sangat beragam dan spesifik pula.

Kompleksitas dan keunikan ekosistem di Pulau Sulawesi disebabkan oleh posisi wilayah dan sejarah biogeografi Pulau Sulawesi. Secara umum ekosistem di Pulau Sulawesi dapat dibedakan menjadi ekosistem tropika basah (hutan hujan tropika) dan ekosistem tropika monsoon (hutan musim tropika). Namun secara lebih rinci, masingmasing ekosistem tersebut tersusun dari subsub ekosistem yang sangat bervariasi dari tempat ke tempat, baik secara altitudinal maupun latitudinal. Selain tipe-tipe ekosistem tersebut, masih terdapat beberapa tipe ekosistem yang keunikannya dipengaruhi oleh kondisi tanah dimana ekosistem tersebut ditemukan, seperti: ekosistem hutan mangrove, ekosistem hutan rawa, ekosistem hutan pantai, ekosistem hutan ultrabasic dan ekosistem karst. Dari setiap ekosistem memiliki keunikannya masing-masing dan tersusun atas spesies flora dan fauna yang berbeda.

Khusus pada jumlah spesies tumbuhan tinggi diperkirakan hanya 5000 spesies, termasuk 2100 tumbuhan berkayu (Whitten et al. 1999). Di pulau Sulawesi hanya didapatkan 7 spesies anggota dari famili Dipterocarpaceae. Menurut Mogea et al. (2001) Sulawesi memiliki tingkat endemisitas palem yang tinggi $(72 \%)$, dimana $68 \%$ spesies dan $58 \%$ genus palem yang tumbuh di bioregion ini adalah asli Sulawesi. Spesies endemik tersebut merupakan spesies yang hanya mampu beradaptasi dengan kondisi 
habitat yang sangat khusus, dan jika habitatnya berubah maka spesies tersebut akan punah. Oleh karena itu, hampir seluruh spesies endemik digolongkan sebagai spesies langka atau rentan terhadap kepunahan. Namun pada sisi lain banyak spesies endemik merupakan spesies yang bernilai ekonomi tinggi seperti kayu eboni, kayu kalapi, kayu uru, beberapa spesies anggrek dan spesies lainnya.

Dukungan terhadap pelestarian dan perlindungan keanekaragaman plasma nutfah hayati di kawasan pulau Sulawesi dilakukan dengan menetapkan beberapa kawasan menjadi kawasan perlindungan, diantaranya Hutan Lindung, Hutan Koservasi dan areal lain di luar kawasan hutan yang diperuntukkan untuk pengelolaan keanekaragaman hayati. Namun demikian, akibat adanya perambahan kawasan, pembukaan dan konversi hutan menjadi daerah transmigrasi, perkebunan, pertanian dan bahkan perluasan pemukiman penduduk, hal ini dapat menurukan tingkat keanekaragaman hayati bahkan mengancam kepunahan spesies-spesies tertentu (Turner et al. 2007; Ahmad et al. 2016).

Periode tahun 2014, Pemerintah Provinsi Sulawesi Selatan telah membentuk Program Pengelolaan Kenakeragaman Hayati dan Ekosistem salah satunya yakni Kabupaten Luwu Utara. Program ini diharapakan dapat mendokumentasikan jumlah spesies yang memiliki potensi dan berstatus endemik. Ditinjau dari letaknya yang spesifik berada di pesisir Teluk Bone pada daerah dataran rendah, dan deretan pegunungan yang membentang berbatasan dengan Sulawesi Tengah dan Sulawesi Barat, memiliki kawasan hutan lindung yang paling luas (419.108 Ha atau 34,25\%) diantara kabupaten yang terdapat di Propinsi Sulawesi Selatan, sehingga sangat mendukung Pengelolaan Keanakeragaman Hayati dan Ekosistem. Apalagi beberapa kawasan hutan lindung telah dijadikan kawasan wisata alam, seperti Hutan Lindung Sarambu' Alla yang selain fungsi utamanaya sebagai kawasan pelestarian sumberdaya plasmanutfah lokal, juga memiliki fungsi tambahan sebagai obyek wisata. Oleh karena itu, eksplorasi terhadap potensi dan pengembangan spesies tumbuhan akan dilakukan untuk mendukung fungsi dan tujuan kawasan hutan dan sebagai dasar acuan dalam kebijakan peningkatan pengelolaan kawasan hutan. Dengan adanya informasi dasar terkait keberadaan keanekaragaman hayati di kawasan tersebut dapat mendukung penyusunan rencana pengelolaan Keanakeragaman Hayati dan Ekosistem bagi pihak yang terkait.

\section{METODOLOGI PENELITIAN}

Kegiatan ini dilaksanakan selama 6 (enam) bulan yaitu Juli sampai Desember 2017 di Hutan Lindung Sarambu' Alla yang terletak di Desa Kalotok, Kecamatan Sabbang, Kabupaten Luwu Utara Propinsi Sulawesi Selatan.

Kegiatan eksplorasi spesies tumbuhan akan dilakukan secara purpossive sampling dengan menggunakan sistem plot tunggal. Hal ini dilakukan dengan mempertimbangkan keterwakilan komunitas tumbuhan, baik komposisi spesies dan struktur vegetasi. Arah jalur ditetapkan sedemikian rupa agar dapat melewati seluruh tipe vegetasi yang ada di dalam kawasan hutan lindung. Di dalam jalur dibuat beberapa plot berukuran $20 \mathrm{~m} \times 20 \mathrm{~m}$.

Semua spesies tumbuhan pohon yang memiliki tinggi $\geq 5 \mathrm{~m}$ ditemukan di dalam setiap plot diukur lingkar (diameter) batangnya pada ketinggian $130 \mathrm{~cm}$ dari permukaan tanah dengan menggunakan pita diameter atau pita meter. Setiap spesies tumbuhan yang ditemukan diambil gambarnya, kemudian bagian tumbuhannya dijadikan spesimen herbarium. Untuk setiap spesimen yang dikoleksi akan dicatat habitusnya, keberadaan dan warna getah, warna corolla (jika ditemukan sedang berbunga), serta kondisi microhabitat.Di 
setiap tempat pengambilan spesimen akan dicatat karakteristik habitat tempat tumbuh spesies tersebut (tepi sungai, lembah, punggung bukit), titik koordinat dan ketinggian tempat (elevasi).

Informasi tentang potensi pemanfaatan tumbuhan diperoleh dengan dua cara, yaitu: pertama adalah data primer dengan cara mewawancarai penduduk lokal yang mengenal dan mengetahui nama-nama lokal dan kegunaan tumbuhan hasil dari kegiatan eksplorasi spesies tumbuhan dengan memperlihatkan sampel spesimen dan foto. Cara kedua diperoleh dari data/informasi sekunder yaitu dari penelusuran pustakapustaka (studi literature) releven yang bersumber dari publikasi ilmiah (jurnal, buku, prosiding dan laporan). Pengelompokan potensi pemanfaatan tumbuhan yang dikoleksi selain didasarkan pada kegunaan utama (primary use) juga kegunaan lainnya (secondary use) (Lemmens et al. 1989). Sedangkan model pengembangan spesies tumbuhan tersebut berdasarkan karakterisitik dan potensinya.

\section{HASIL DAN PEMBAHASAN}

\section{Potensi Spesies Tumbuhan}

Hutan Lindung Sarambu Alla memiliki potensi spesies tumbuhan yang mempunyai manfaat untuk dikembangkan baik bernilai ekonomi maupun ekologi. Hasil penelitian menunjukkan bahwa terdapat 64 spesies yang ditemukan pada 25 plot pengamatan. Selanjutnya dari jumlah spesies yang ditemukan, 32 spesies habitus pohon memiliki potensi sebagai tumbuhan berguna. Informasi ini diharapakan dapat menjadi salah satu acuan model pengembangan bagi masyarakat, sehingga dapat melakukan budidaya pada lahan miliknya tanpa harus masuk dalam kawasan hutan untuk melakukan penebangan atau illegal logging yang berdampak pada kerusakan hutan.

Potensi dan manfaat spesies yang telah diidentifikasi dan diketahui nama spesiesnya, diklasifikasikan berdarkan kegunaan dan manfaatnya yaitu sebagi konstruksi bahan bangunan, furniture (meubel), kerajinan (hiasan/assesori), tanaman obat, pulp dan kayu lapis (veneer/cabinetwork), tanaman pangan (konsumsi), kosmetik, tanaman hias (estetika), tanaman reboisasi dan pelindung, peralatan (musik, perkakas, pertanian), dan penghasil zat pewarna (Gambar 1). Terdapat 19 spesies spesies yang ditemukan berpotensi nilai kayunya sebagai bahan bangunan dan konstruksi. Spesies yang dimanfaatkan buah dan dan bagian lain untuk dikonsumsi dan dijadikan sebagai obat tradisional atau herbal masing-masing sebanyak 16 spesies. Khusus spesies yang dimanfatakan kayunya sebagai peralatan sebanyak 12 spesies, penggunaan untuk furniture 11 spesies, serta pulp dan kayu lapis sebanyak 9 spesies. Sedangkan spesies yang berpotensi sebagai zat pewarna dan kerajinan memiliki jumlah spesies yang sangat sedikit yaitu masing-masing 4 spesies. Adapun spesies yang berpotensi sebagai bahan kosmetik, tanaman hias dan tanaman reboisasi masing-masing memiliki jumlah spesies secara beruruta yaitun 5, 6, dan 9 spesies (Gambar 3).

Adapun spesies yang memiliki potensi yang sangat bagus berdasarkan kriteria kelas kayu diantaranya Betao (Calophyllum soullatri Burmn.f), Nato (Phoebe grandis (Nees) Merr.), Sinangkala (Litsea mappacea Boerl.), Palli (Lithocarpus sundaicus (Blume) Rehder), dan Uru (Magnolia lilifera Druce). Spesies berpotensi selain kayunya dimanfaatkan tetapi memiliki khasiat obat dan dapat dikonsumsi antara lain: Dengen (Dillenia serrata Thunb.), Tarra (Artocarpus elasticus Reinw. ex Blume), Budao (Allophylus cobbe (L.) Raeusch), Langsat Hutan (Lansium parasiticum (Osbeck) K.C. 
Volume 1 Nomor 1 Juli 2019: 34-41

Sahni \& Bennet Syn. Lansium domesticum Correa), Palauk (Maccadamia hildebrandii Steenis), Sirri (Flacourtia rukam Zoll. \& Moritzi), dan Kadinge (Cinnamomum burmanni (Nees \& T. Nees) Blume). Spesies yang berpotensi sebagai bahan kosmetik seperti Uru (Magnolia lilifera Druce), Langsat Hutan (Lansium parasiticum (Osbeck) K.C. Sahni \& Bennet Syn. Lansium domesticum Correa), Betao (Calophyllum soullatri Burmn.f), dan Kadinge (Cinnamomum burmanni (Nees \& T. Nees) Blume). Khusus spesies yang memiliki manfaat sebagai bahan berpotensi sebagai tanamana hias diantaranya Kadinge (Cinnamomum burmanni), Malapare (Gironniera subaequalis Planch.), Polio (Melicope bonwickii F.Muell.), Dengen (Dillenia serrata Thunb.) dan Palauk (Maccadamia hildebrandii Steenis). Sedangkan spesies yang mempunyai manfaat sebagai tanaman reboisasi antara lain Palli (Lithocarpus sundaicus), Uru (Magnolia lilifera Druce), Langsat Hutan (Lansium kerajinan yaitu Elaeocarpus spp., Lebani (Neonauclea excelsa (Blume) Merr.), dan Poringan (Cratoxylum sumatranum (Jack) Blume) (disajikan pada Tabel 1).

Selain itu, terdapat pula spesies tumbuhan yang berpotensi sebagai pewarna, tanaman hias dan tanaman reboisasi. Adapun spesies tumbuhan yang memiliki kegunaan sebagai pewarna terdiri dari: Betao (Calophyllum soullatri Burmn.f), Dengen (Dillenia serrata Thunb.), dan Lumi (Mangifera spp. L.). Spesies tumbuhan yang

parasiticum), Landung (Allophylus cobbe (L.) Raeusch), Malapare (Gironniera subaequalis Planch.), dan Polio (Melicope bonwickiiF.Muell.). terdapat satu spesies yang sangat berpotensi yaitu Kalam Buto (Taberneamontana pandacaqui Lam.) memiliki tiga manfaat sekaligus baik sebagai bahan pewarna, tanaman hias dan tanaman reboisasi

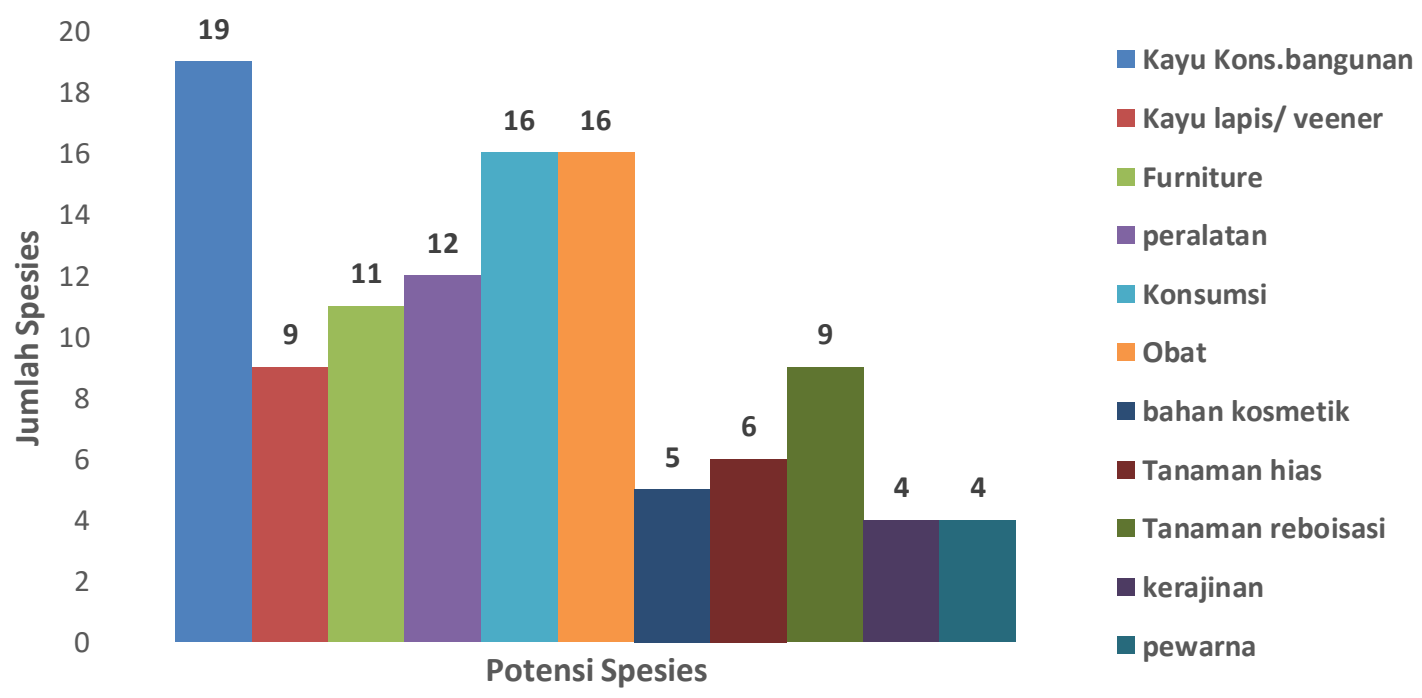

Gambar 1 Potensi Tumbuhan Berguna dan Jumlah Spesies di Hutan Lindung Sarambu Alla

\section{Model Pengembangan Spesies Tumbuhan}

Spesies yang memiliki potensi sebagai tumbuhan berguna, sebaiknya dilakukan model pengembangan spesies yaitu 
salah satunya dibudidayakan pada lahan milik masyarakat khususnya spesies yang memiliki nilai ekonomi dan komersial. Pembudidayaan spesies komersial dapat dilakukan pada lahan milik masyarakat seperti hutan rakyat, kebun dan pekarangan. Hal ini dilakukan agar masyarakat tidak lagi menebang pohon dalam kawasan hutan lindung, karena pada lahan milikinya sudah tersedia.

Demikian pula pada spesies yang memiliki nilai ekologi dan khas atau endemik lokal sebaiknya dapat menjadi tanaman koleksi sebagai sumber plasma nutfah pada ruang terbuka hijau (RHT) seperti Hutan Kota, Jalur Hijau/Green Belt, Taman Hutan Raya dan Taman Keanekeragaman Hayati. Selain itu, ada beberapa spesies yang sifatnya merupakan tumbuhan pionir dan spesies cepat tumbuh, sebaiknya spesies tersebut dikembangkan untuk ditanam pada lahan dan kawasan hutan yang telah rusak melalui kegiatan reboisasi atau rehabilitasi hutan dan lahan. Spesies yang memiliki status endemik baik endemik lokal maupun pulau seperti Iasa (Lithocarpus celebicus (Miq.)), Aropi (Antidesma celebica?syn. Baccaurea javanica (Blume) Muii.Arg.) dan Durian (Durio zibethinus L.) khususnya Durian Sawerigading dan Durian Baka-baka sebaiknya diperbanyak dengan dibudidayakan pada lahan milik, dijadikan tanaman koleksi sebagai sumber plasma nutfah yang dikembangkan pada ruang terbuka hijau (RTH).

Berdasarkan Tabel 1 terlihat bahwa spesies pohon yang ada di Hutan Lindung Sarambu Alla' memiliki potensi yang cukup baik untuk dimanfaatkan. Hal yang perlu diperhatikan dalam setiap bentuk pemanfaatan masing-masing jenis adalah upaya untuk melakukan budidaya. Bentuk kegiatan budidaya spesies yang dapat dilakukan adalah dengan penanaman pada lahan perkebunan dengan teknik agroforestry (pada lahan pribadi). Selain itu, pada lahan publik (negara) dapat dilakukan dengan menjadikan spesies tertentu sebagai tanaman rehabilitasi lahan, pembangunan kebun raya atau arboretum kota, maupun dalam bentuk hutan kota. Setiap bentuk upaya pemanfaatan dan budidaya dalam rangka pelestarian spesies khususnya spesies endemik, hanya bisa dilakukan dengan dukungan berbagai pihak serta kebijakan dan political will yang berpihak pada tujuan pemanfaatan spesies secara lestari.

Tabel 1. Potensi dan model pengembangan spesies tumbuhan yang terdapat di Hutan Lindung Sarambu Alla

\begin{tabular}{|l|l|}
\hline Potensi Pemanfaatan & Model Pengembangan \\
\hline Kayu konstruksi bangunan & $\begin{array}{l}\text { Tumbuhan ini baik untuk dibudidayakan pada Hutan Rakyat karena } \\
\text { memiliki manfaat khususnya kayu }\end{array}$ \\
\hline Kayu lapis/veneer & $\begin{array}{l}\text { Budidaya di lahan kebun atau pekarangan mayarakat. Selain itu, dapat } \\
\text { dijadikan tanaman reboisasi pada daerah dataran rendah sampai } \\
\text { perbukitan }\end{array}$ \\
\hline Konsumsi & $\begin{array}{l}\text { Pengembangan jenis pohon untuk obat-obatan dapat dilakukan dengan } \\
\text { dibudidayakan pada Hutan Rakyat karena memiliki manfaat kayu dan } \\
\text { HHBK (buahnya) }\end{array}$ \\
\hline Obat-obatan & $\begin{array}{l}\text { Tanaman peneduh dan tanaman hias karena memiliki habitus yang baik } \\
\text { dan bunganya yang indah. Sangat baik dikembangkan sebagai tanaman } \\
\text { koleksi arboretum atau hutan kota }\end{array}$ \\
\hline Tanaman Hias & $\begin{array}{l}\text { Taman Hutan Raya (Tahura), Hutan Kota dan Taman Kehati } \\
\text { (Keanekaragaman Hayati) }\end{array}$ \\
\hline Tanaman reboisasi & $\begin{array}{l}\text { Tumbuhan ini baik untuk dibudidayakan pada Hutan Rakyat karena } \\
\text { memiliki manfaat kayu dan HHBK (buahnya) }\end{array}$ \\
\hline Bahan kerajinan & \multicolumn{2}{|}{} \\
\hline Pewarna &
\end{tabular}




\section{KESIMPULAN DAN SARAN}

Berdasarkan hasil eksplorasi dan identifikasi spesies tumbuhan memiliki potensi pada Hutan Lidung Sarambu' Alla, dapat ditarik kesimpulan bahwa terdapat terdapat 32 spesies habitus pohon yang memiliki potensi sebagai tumbuhan berguna dan dapat dimanfaatkan, meliputi 19 spesies berpotensi sebagai bahan bangunan. Spesies yang dimanfaatkan untuk pangan dan sebagai obat tradisional masing-masing sebanyak 16 spesies. Khusus spesies yang dimanfatakan kayunya sebagai peralatan sebanyak 12 spesies, penggunaan untuk furniture 11 spesies, serta pulp dan kayu lapis sebanyak 9 spesies. Sedangkan spesies yang berpotensi sebagai zat pewarna dan kerajinan memiliki jumlah spesies yang sangat sedikit yaitu masing-masing 4 spesies. Adapun spesies yang berpotensi sebagai bahan kosmetik, tanaman hias dan tanaman reboisasi masingmasing memiliki jumlah spesies secara berurutan yaitun 5, 6, dan 9 spesies. Selain itu, spesies tumbuhan yang memiliki potensi dan dimanfaatkan, menjadi model pengembangan

\section{DAFTAR PUSTAKA}

Ahmad, A., Saleh, M. B., \& Rusolono, T. (2016). Model Spasial Deforestasi di KPHP Poigar, Provinsi Sulawesi Utara. Jurnal Penelitian Kehutanan Wallacea, 5(2), 159-169.

Badan Pusat Statistik (BPS), 2017. Kabupaten Luwu Utara dalam Angka 2017. Badan Pusat Statistik Kabupaten Luwu Utara. Dapat diakses online (http://portal.luwuutarakab.go.id/conte nt/uploads/images/dokumen/lutra- spesies bagi masyarakat. Terutama pengembangan budidaya pada lahan miliknya tanpa harus masuk dalam kawasan hutan untuk melakukan penebangan atau illegal logging yang berdampak pada kerusakan hutan. Tumbuhan yang memiliki nilai ekologi dan khas atau endemik lokal, dapat dikembangkanat menjadi tanaman koleksi sebagai sumber plasma nutfah pada ruang terbuka hijau (RHT) seperti Hutan Kota, Jalur Hijau/Green Belt, Taman Hutan Raya dan Taman Keanekeragaman Hayati. Saran dari penelitian ini adalah Spesies tumbuhan yang potensial di Hutan Lindung Sarambu Alla perlu upaya pengembangan dan budidaya di lahan milik masyarakat sebagai salah satu cara agar masyarakat tidak masuk ke dalam kawasan hutan lindung, sehingga kelestarian hutan lindung tersebut tetap terjaga. Demikian pula, Sosialisasi kepada masyarakat mengenai pentingnya hutan lindung sebagai penyangga kehidupan perlu ditingkatkan dan pengawasan lebih dioptimalkan khususnya di daerah pinggir yang berbatasan langsung dengan perkampungan dan aktifitas masyarakat.

dalam-angka/Kabupaten-Luwu-UtaraDalam-Angka-2017.pdf). Diakses 20 Desember 2017.

Indriyanto, 2006. Ekologi Hutan. PT. Bumi Aksara, Jakarta.

Lemmens, R.H.M.J., P.C.M. Jansen, J.S. Siemosma and F.M. Stavast (eds.). 1989. Basic List of Species and Commodity Grouping Version. Wageningen: Plant Resources of South-East Asia (PROSEA)

Mogea, J.P., Gandawijaya, H. Wiriadinata, R.E. Nasution, dan Irawati. 2001. 
Tumbuhan Langka Indonesia Vol.1. Pusat Penelitian dan Pengembangan Biologi-LIPI. Balai Penelitian Botani, Herbarium Bogoriense.

Sofiah, D. 2007. Keragaman Jenis Anakan Tingkat Semai dan Pancang di Hutan Alam. Karya Tulis, USU Repository. Fakultas Pertanian Universitas Sumatera Utara, Medan.

Tommo. 2007. Keanekaragaman Hayati. (http://myjourneystommo.blogspot.com/2007/ 12/keanekaragaman-hayati.html.). Diakses 07 Agustus 2017.

Turner BL, Lambin EF, Reenberg A. 2007. The emergence of land change science for global environmental change and sustainability. Proceedings of the National Academy of Sciences. 104(52):20666-20671.

Uji, T., 2005. Keanekragaman dan Potensi Flora di Suaka Margasatwa Buton
Utara Sulawesi Tenggara. Biodiversitas. Vol. 6 No. 3: Hal. 205211. LIPI Bogor.

Wahyuningsih, M.S.H., S. Wahyuono, D. Santosa, J. Setiadi, Soekotjo, S.M. Widiastuti, R. Rakhmawati, dan D.S.C. Wahyuni. 2008. Eksplorasi Tumbuhan dari Hutan Kalimantan Tengah Sebagai Sumber Senyawa Bioaktif. Biodiversitas Volume 9 No. 3 (hal. 169 - 172). Dapat diakses online

(http://biodiversitas.mipa.uns.ac.id/D/ D0903/D090303.pdf). Diakses 07 Agustus 2017.

Whitten, J. A., M. Muslimin and G. S. Henderson. 1999. Ekologi Sulawesi (Terjemahan). Gadjah Mada University Press, Yogyakarta 